\title{
Efficient Persulphate Mediated Electrooxidation of Substituted Benzyl Alcohols in Biphasic Media
}

\author{
A.ViniPriya, A.John Bosco, T. Maiyalagan", N. Xavier ${ }^{*}$, D. Vasudevan \\ * Department of Chemistry, St.Joseph's College, Tiruchirapalli, Tamilnadu, India \\ Department of Chemistry, SRM University, Faculty of Science and Humanities, \\ Kattankulathur- 603 203, Chennai, India \\ * SRM Research Institute, Department of Chemistry, SRM University, Kattankulathur-603203, \\ Chennai, India \\ Electrodics Division, Central Electrochemical Research Institute, Karaikudi, Tamilnadu, India \\ ${ }^{*}$ E-mail: maiyalagan@gmail.com
}

doi: $10.20964 / 2017.02 .07$

Received: 13 September 2016 / Accepted: 18 November 2016 / Published: 30 December 2016

This paper discusses the electro oxidative conversion of $p$-methoxybenzylalcohol ( $p$-MBA) to $p$-anisaldehyde which was effected at a graphite anode in a biphasic media using persulphate as the mediator. Electrolysis conditions were optimized based on current density, electrode material, temperature, solvent, inorganic salt mediator and $\mathrm{pH}$ of the reaction system. The present investigation endowed with excellent yield of $p$-anisaldehyde (97\%) under the best reaction conditions by tuning the electrolysis conditions along with a simple reaction set up .The optimized conditions were extended for the oxidation of other substituted benzyl alcohols and promising yields were obtained. A plausible mechanism for the oxidation of $p$-methoxy benzyl alcohol has been proposed.

Keywords: Selective oxidation, Biphasic media, Green Chemistry, Electro oxidation, Redox reaction $p$-methoxybenzyl alcohol

\section{FULL TEXT}

(C) 2017 The Authors. Published by ESG (www.electrochemsci.org). This article is an open access article distributed under the terms and conditions of the Creative Commons Attribution license (http://creativecommons.org/licenses/by/4.0/). 